\title{
Resolver Device Component
}

National Cancer Institute

\section{Source}

National Cancer Institute. Resolver Device Component. NCI Thesaurus. Code C50142.

A motor designed to interchang rectangular and polar coordinates or the TCP/IP software that sends requests to the Domain Name Server. 